\title{
Spectral Line Competition in a Coaxial Electron-Beam- Pumped High Pressure Ar/Xe Laser
}

\author{
Y. F. Lan ${ }^{\star}$, P. J. M. Peters, and W. J. Witteman \\ University of Twente, Department of Applied Physics, P.O. Box 217, NL-7500 AE Enschede, The Netherlands
}

Received 14 November 1990/Accepted 10 January 1991

\begin{abstract}
In order to study the kinetic mechanism of the e-beam pumped $\mathrm{Ar} / \mathrm{Xe}$ laser, the temporal profiles of individual laser lines during multiline oscillation have been measured as a function of power deposition (1-12 MW/ $\mathrm{cm}^{3}$ ) and gas laser pressure (2-14 bar) using a short pulse $(30 \mathrm{~ns})$ coaxial electron beam as excitation source. It was found that the optimum output energy at each pressure was obtained at the same specific power deposition.

Strong line competition has been observed between the 2.65 and $1.73 \mu \mathrm{m}$ transitions. In order to explain our results we suggest that besides electron collision mixing (ECM) between the $5 d$ and $6 p$ levels of Xe, there is also a redistribution between all $6 p$ levels which strongly favours the lower levels at higher pumping densities.
\end{abstract}

PACS: $34.80 \mathrm{D}, 41.80 \mathrm{Dd}, 42.55 \mathrm{~F}$

The atomic xenon infrared laser has attracted the attention of researchers since an electrical efficiency of nearly $1 \%$ was reported for this laser by Newman and DeTemple using an electron beam preionized discharge [1]. The atomic xenon laser operates on six infrared transitions $(1.73 \mu \mathrm{m}-3.51 \mu \mathrm{m})$ between the $5 d$ and $6 p$ manifold (Fig. 1). An intrinsic efficiency of about $5 \%$ with a maximum specific output energy of $8 \mathrm{~J} /$ liter was reported in 1985 by Basov et al. [2]. Recently is was observed that an e-beam sustained system has the potential of about $9 \%$ intrinsic efficiency [3]. The laser operates in various modes such as an electric discharge mode $[4,5]$, with electron-beam excitation $[6,7]$, with an electron beam sustained discharge $[2,3,8]$, fission fragment excited [9], and in a microwave discarge [10]. Power depositions of $10 \mathrm{~W} / \mathrm{cm}^{3} \cdot$ bar to $1 \mathrm{MW} / \mathrm{cm}^{3} \cdot$ bar, pumping pulse durations of $10 \mathrm{~ns}-5 \mathrm{~ms}$, and total gas pressures of $0.5-14 \mathrm{bar}$ in a mixture consisting of $0.01-10 \%$ of xenon in rare gas buffers ( $\mathrm{He}, \mathrm{Ne}, \mathrm{Ar}, \mathrm{Kr}$ ) have been investigated. Since the most promising laser performance has been obtained in $\mathrm{Ar} / \mathrm{Xe}$ mixtures with electron-beam pumping and electron-beam sustained discharge pumping, most experimental work has been carried out on those systems. Recently there has been increased interest in studying the kinetic mechanism [11]. As the atomic xenon laser

\footnotetext{
* Permanent address: Institute of Electronics, Academia Sinica, Beijing, P.R. China
}

is a highly complicated laser system, little is understood about the fundamental kinetic mechanism which is responsible for the performance of the laser. In order to study the kinetic processes of the Ar/Xe laser, we have operated the laser with a short pulse table-top coaxial electron beam source. Measurements of the delay times of the various laser lines with respect to the pumping pulse as a function of different total gas pressures and power deposition rates have already been made [12].

In this paper the temporal profiles of the individual laser lines have been studied in a large parameter space. The results of these measurements will be presented and discussed with respect to the line competition. We found

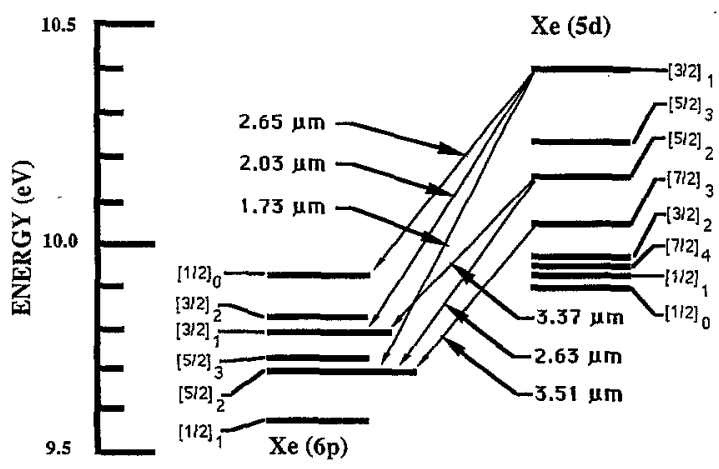

Fig. 1. Scheme of laser levels of the Xe atom 
that there is a strong spectral line competition. Especially at optimum excitation conditions which correspond to a maximum output energy, strong competition occurs between the $1.73 \mu \mathrm{m}$ and $2.65 \mu \mathrm{m}$ transitions. Although they share the same lower laser level little competition appears between the $1.73 \mu \mathrm{m}$ and the $2.63 \mu \mathrm{m}$ transitions. It has been found that under optimum excitation conditions the specific power depositions almost keep the same value within a large parameter space (mixture pressure of 2-14 bar, power deposition of $\left.0.9-6.0 \mathrm{MW} / \mathrm{cm}^{3}\right)$. The experimental evidence suggests that a redistribution of the population between all $6 p$ levels as a function of the pumping power and total gas pressure plays a very important role in the laser kinetics of the e-beam pumped $\mathrm{Ar} / \mathrm{Xe}$ laser.

\section{Experimental Apparatus}

All experiments described in this paper have been performed with a table-top coaxial e-beam apparatus. The system was able to excite a high pressure gas (up to $18 \mathrm{bar}$ ) in a very uniform way by means of a coaxial e-beam with high energy electrons at a high current density. This system consisting of a coaxial vacuum diode driven by a low-inductance ten-stage Marx generator has been described in detail previously [12]. The anode of this diode was a thin titanium tube with a wall thickness of $50 \mu \mathrm{m}$ or $25 \mu \mathrm{m}$. The inner diameter of the tube was $10 \mathrm{~mm}$. The pumped length of the anode tube is $20 \mathrm{~cm}$. The total stored energy in the Marx generator is about $100 \mathrm{~J}$ at the maximum load voltage of $60 \mathrm{kV}$ per stage. The maximum impedance matched diode voltage is about $300 \mathrm{kV}$ with a peak diode current of $7.5 \mathrm{kA}$. The current pulse width is about $30 \mathrm{~ns}$ (FWHM).

The optical resonator and diagnostic arrangement are shown in Fig. 2. The resonator with a length of $400 \mathrm{~mm}$ consists of a gold coated total reflecting mirror with a radius of curvature of $2 \mathrm{~m}$ on one side, and a plane parallel uncoated $\mathrm{ZnSe}$ flat on the other side. The output radiation was dispersed in a Hilger and Watts monochromator with a focal length of $30 \mathrm{~cm}$ and equipped with a $1501 / \mathrm{mm}$ grating blazed at $4 \mu \mathrm{m}$. The diffracted signal of the grating was detected by an uncooled $\mathrm{InSb}$ ORP-10 detector. The detector signal was displayed on a Tektronix R7912AD oscilloscope which was externally triggered by a current signal from the Marx generator.
In order to ensure good reproducibility of the measurement results, it is necessary that the resonator and the diagnostic arrangement can be aligned carefully. This alignment was accomplished by means of a $\mathrm{He}-\mathrm{Ne}$ laser along the solid line trace as indicated in Fig. 2. During the alignment the beam was positioned through the irises $r_{1}$ and $r_{2}$. The same irises $r_{1}$ and $r_{2}$ could also be used for aligning the monochromator and the detector with the laser system after removing $\mathrm{M}_{3}$ and $\mathrm{M}_{4}$ as indicated by the dashed line.

\section{Experimental Results}

According to our previous experimental results the optimum laser gas composition in the laser chamber has to be $0.3-0.4 \% \mathrm{Xe}$ in Ar. This gas mixture was used in the present experiments. The delay time as a function of the power deposition rate has already been measured at different pressures of the gas mixture for the $50 \mu \mathrm{m} \mathrm{Ti}$ anode tube [12]. We recorded the temporal line shapes of the four most important laser lines at various load voltages of the Marx generator and for various pressures up to 14 bar. From these signals we could deduce the optical delay times and pulse widths $[6,12]$. Moreover after integration of these signals we were able to calculate the rate of change in energy of the individual laser lines. Due to different response of the optical detection system for various wavelengths it was not possible in this way to estimate the exact contribution of each line to the total energy.

The temporal behaviour of a typical set of laser lines is shown in Fig. 3. The output profiles of the $1.73 \mu \mathrm{m}$, the $2.63 \mu \mathrm{m}$ and the $2.65 \mu \mathrm{m}$ transitions are plotted in this figure for the optimum excitation conditions which correspond to the maximum output energy for the $25 \mu \mathrm{m}$ Ti anode tube. It can be seen that the pulse widths of all lines decrease with increasing total gas pressure. Apart from some spikes of the $2.65 \mu \mathrm{m}$ line at a low gas pressure it can also be seen that the delay times decrease with increasing pressure. In Fig. 3 it is seen that at the optimum excitation conditions the 1.73 and $2.63 \mu \mathrm{m}$ laser lines start almost simultaneously whereas the oscillation of the $2.65 \mu \mathrm{m}$ line starts a few nanoseconds earlier. These three strongest laser lines have the best population inversion condition for the optimum excitation condition at the same time. Furthermore it is seen that the energy of

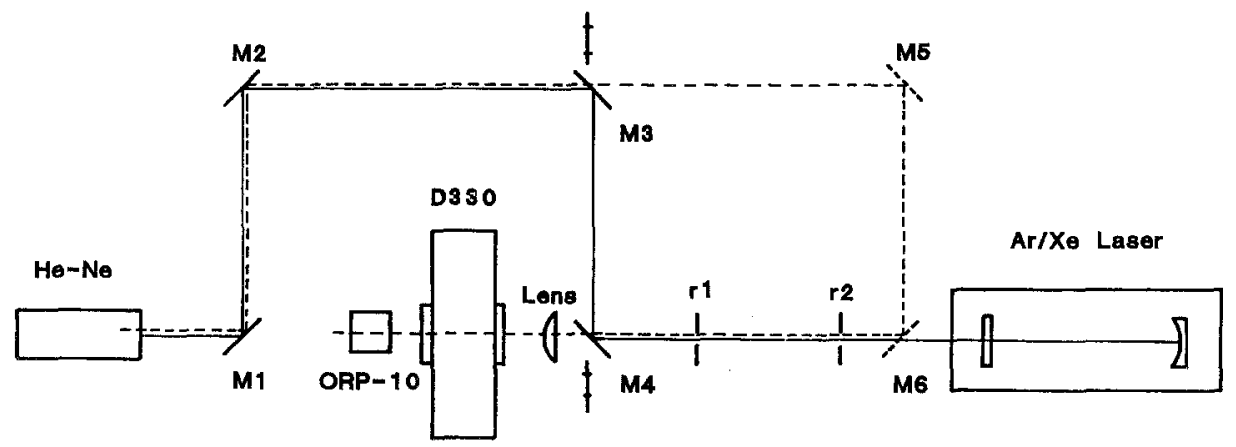

Fig. 2. Schematic illustration of the experimental atrangement 

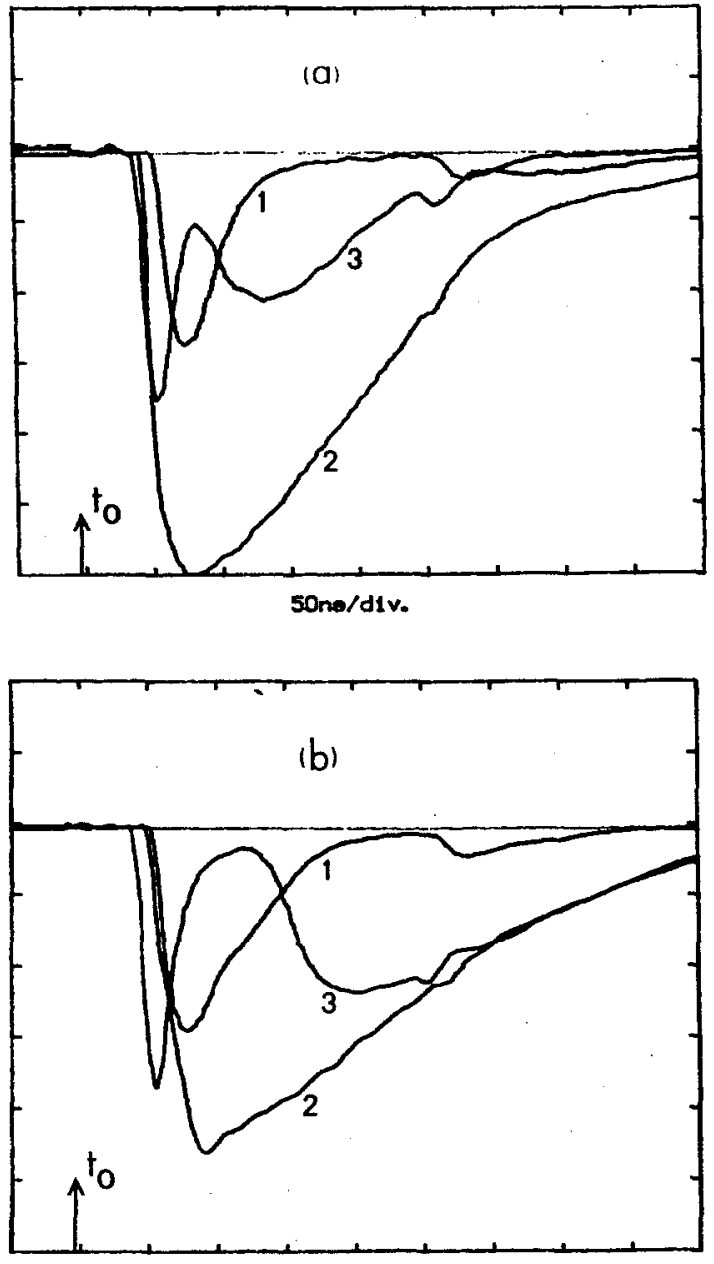

5one/div.

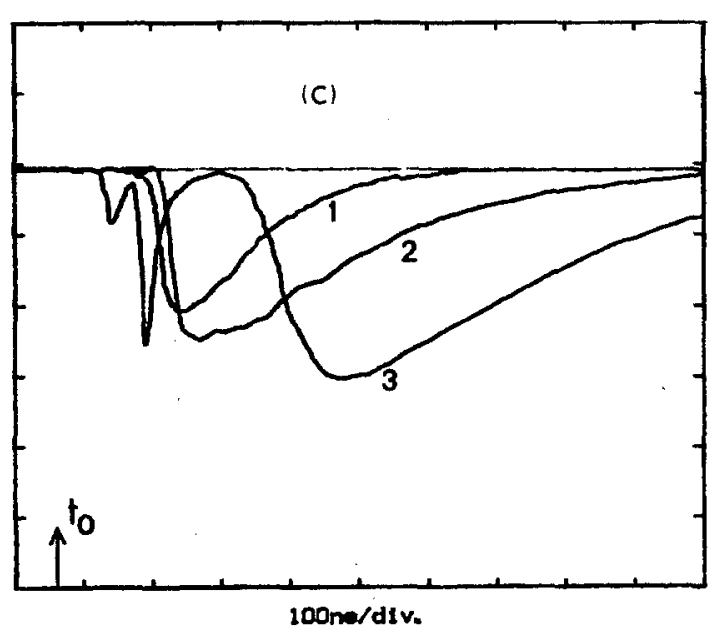

Fig. 3a-c. Temporal profiles of the $1.73 \mu \mathrm{m}(1), 2.63 \mu \mathrm{m}$ (2), and $2.65 \mu \mathrm{m}$ (3) lines at maximum output energy for different total gas pressure and power deposition $(0.4 \% \mathrm{Xe}$ in $\mathrm{Ar}, 25 \mu \mathrm{m} \mathrm{Ti}$ tube). a $14 \mathrm{bar}, 6.3 \mathrm{MW} / \mathrm{cm}^{3}$, b $10 \mathrm{bar}, 4.3 \mathrm{MW} / \mathrm{cm}^{3}$, and c $4 \mathrm{bar}$, $2.1 \mathrm{MW} / \mathrm{cm}^{3}$. The arrow marks the starting point of the excitation pulse

the $2.63 \mu \mathrm{m}$ lines compared to that of the $1.73 \mu \mathrm{m}$ line increases with increasing gas pressure. The competition processes between the $1.73 \mu \mathrm{m}$ and $2.65 \mu \mathrm{m}$ transitions are shown very clearly in Fig. 3.

\section{Discussion}

We almost never observed laser oscillation during the e-beam current pulse. In most cases laser pulses of $100 \mathrm{~s}$ of ns duration have been obtained starting $60-800 \mathrm{~ns}$ after the termination of the excitation current pulse. It was observed that for the laser lines of the $1.73 \mu \mathrm{m}$ and $2.63 \mu \mathrm{m}$ transitions the measured delay times increased with increasing power deposition. A different behaviour was found for the $3.37 \mu \mathrm{m}$ transtition. Here the delay time decreased with increasing power deposition [12].

The above mentioned results reflect the quite complicated kinetic processes in the e-beam pumped $\mathrm{Ar} / \mathrm{Xe}$ laser. It is believed that laser excitation and quenching results from dissociative recombination of $\mathrm{ArXe}^{+}$and $\mathrm{Xe}_{2}^{+}$ respectively. The dissociative recombination of $\mathrm{ArXe}^{+}$ populates almost directly the $5 d$ manifold of $\mathrm{Xe}$, while the dissociative recombination of $\mathrm{Xe}_{2}^{+}$leads directly to the $6 p$ manifold. Peters et al. [12] have investigated some of the excitation mechanisms for the e-beam pumped $\mathrm{Ar} / \mathrm{Xe}$ laser with a computer model using the above mentioned experimental results. It was found that electron collision mixing (ECM) of the laser levels is responsible for the time delay for oscillations at high power deposition condition $\left(1-10 \mathrm{MW} / \mathrm{cm}^{3}\right)$.

Within a large parameter space, namely the total gas mixture pressure form 4 to 14 bar and power deposition from 1.7 to $6.0 \mathrm{MW} / \mathrm{cm}^{3}$ very strong competition has been observed between the $1.73 \mu \mathrm{m}$ and $2.65 \mu \mathrm{m}$ transitions. They both share the same upper laser level $5 d[3 / 2]_{1}$. The $2.65 \mu \mathrm{m}$ transition always starts to lase before the $1.73 \mu \mathrm{m}$ transition. As can be seen in Fig. 3, the optical pulse of the $2.65 \mu \mathrm{m}$ transition immediately starts to decay at the onset of the $1.73 \mu \mathrm{m}$ oscillation. When the lasing of the $1.73 \mu \mathrm{m}$ transition reaches its maximum, the output of the $2.65 \mu \mathrm{m}$ transition decreases to a minimum. In the meantime the thermalization over all $6 p$ levels takes place so that the population of Xe $6 p[1 / 2]_{0}$ level will be reduced. This again favours the oscillation of the $2.65 \mu \mathrm{m}$ transition. In this way the intensity of the $1.73 \mu \mathrm{m}$ line decreases and the intensity of the $2.65 \mu \mathrm{m}$ line recovers almost totally. Thus the temporal behaviour of the $2.65 \mu \mathrm{m}$ line shows a dip reflecting the competition with the $1.73 \mu \mathrm{m}$ line (Fig. 3). The width of this dip, defined as the width between the top of the spike before the dip and the following maximum, is almost equal to the width of the $1.73 \mu \mathrm{m}$ optical pulse at $10 \%$ of its maximum.

In Fig. 4 we have plotted the width of the dip in the $2.65 \mu \mathrm{m}$ optical pulse and the width of the $1.73 \mu \mathrm{m}$ optical pulse as a function of the pressure of the laser gas mixture. The values plotted in this figure have been obtained at the optimum pumping condition which corresponds to the maximum output energy for each particular pressure. It is seen that both the pulse and dip width are equal and change in the same way over the whole pressure range.

We further noted that when the total laser gas pressure is changed from 2 bar to 14 bar and the power deposition is increased from 0.5 to $16 \mathrm{MW} / \mathrm{cm}^{3}$, the specific power deposition for the optimum pumping condition is almost constant. This is shown in Table 1. 


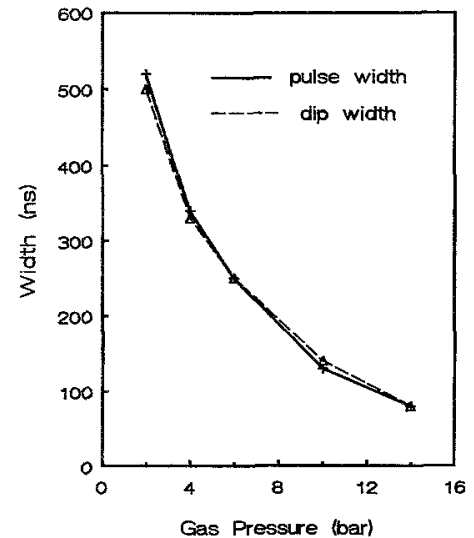

Fig. 4. Width of the valley for the $2.65 \mu \mathrm{m}$ optical pulse $(\Delta)$ together with the width of the pulse for the $1.73 \mu \mathrm{m}$ optical pulse $(+)$ as a function of the total gas pressure (optimum excitation conditions)

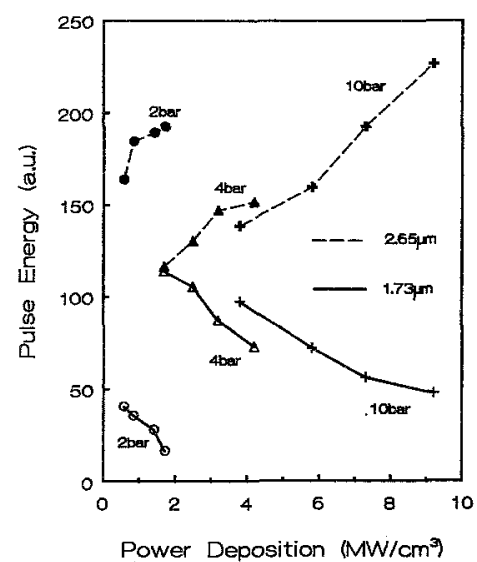

Fig. 5. Integrated energy of the optical pulse of the $1.73 \mu \mathrm{m}$ and $2.65 \mu \mathrm{m}$ lines as a function of power deposition at total gas pressure of 2,4 , and 10 bar

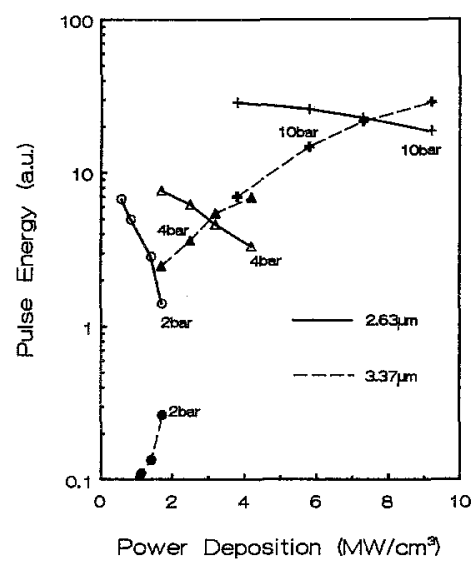

Fig. 6. Integrated output energy for the $2.63 \mu \mathrm{m}$ and $3.37 \mu \mathrm{m}$ laser lines as a function of the power deposition at three different total gas pressures

The ECM process will also thermalize the $6 p$-manifold. By this process the population of the $6 p[5 / 2]_{2}$ level will increase whereas the population of the $6 p[1 / 2]_{0}$ level will decrease. From this mechanism it is understandable that the intensity of the $2.65 \mu \mathrm{m}$ line will increase at the expense of the $1.73 \mu \mathrm{m}$ line as a function of the power
Table 1. Specific power deposition at optimum excitation conditions for $0.4 \% \mathrm{Xe}$ in $\mathrm{Ar}$

\begin{tabular}{lll}
\hline $\begin{array}{l}\text { Total gas } \\
\text { pressure } \\
{[\text { bar] }}\end{array}$ & $\begin{array}{l}\text { Optimum power } \\
\text { deposition } \\
{\left[\mathrm{MW} / \mathrm{cm}^{3}\right]}\end{array}$ & $\begin{array}{l}\text { Specific power } \\
\text { deposition } \\
{\left[\mathrm{MW} / \mathrm{cm}^{3} \text { bar }\right]}\end{array}$ \\
\hline 2 & 0.88 & 0.44 \\
4 & 1.70 & 0.43 \\
6 & 2.67 & 0.44 \\
10 & 4.23 & 0.42 \\
14 & 5.94 & 0.42 \\
\hline
\end{tabular}

deposition. For similar reasons the thermalization of the $5 d$-manifolds leads to a higher population density of the $5 d[5 / 2]_{2}$ and consequently to a higher intensity of the $2.63 \mu \mathrm{m}$ line. These thermalization processes are more effective at higher pressures as can also be seen from Fig. 3.

In Fig. 5 the integrated energy of the optical pulses of the $1.73 \mu \mathrm{m}$ and $2.65 \mu \mathrm{m}$ line as a function of the power deposition is shown. From this figure it is seen that the optical pulse energy of the $1.73 \mu \mathrm{m}$ transition always decreases with increasing power deposition and that the optical pulse energy of the $2.65 \mu \mathrm{m}$ transition increases with increasing power deposition.

In Fig. 6 the integrated output energies are plotted for the $2.63 \mu \mathrm{m}$ and $3.37 \mu \mathrm{m}$ lines as a function of the power deposition. It can be seen that the increase of the $3.37 \mu \mathrm{m}$ line goes at the expense of the $2.63 \mu \mathrm{m}$ line. This can also be explained by the increased thermalisation process of the lower $5 d$ levels with the current density.

\section{Conclusion}

Through observations of the temporal behaviour of individual laser lines as a function of power deposition and gas pressure it has been found that the optical pulse energy of the $1.73 \mu \mathrm{m}$ and $2.63 \mu \mathrm{m}$ lines decrease with increasing power deposition. We also observed strong competition between the $1.73 \mu \mathrm{m}$ and $2.65 \mu \mathrm{m}$ lines. These competition effects can be understood from a thermalization process and by the fact that several transitions share a common upper level or a common lower level.

Acknowledgements. These investigations in the program of the Foundation for Fundamental Research on Matter (FOM) have been partly supported by the Netherlands Technology Foundation.

We are also very grateful to Mark J.Kushner (University of Illinois, USA) for his stimulating comments on the content of this paper.

\section{References}

1. L.A. Newman, T.A. DeTemple: Appl. Phys. Lett. 27, 678-680 (1975)

2. N.G. Basov, V.V. Baranov, A.Y. Chugunov, V.A. Danilychev, A.Y. Dudin, I.V. Kholin, N.N. Ustinovskii: IEEE J. QE-21, 1756-1760 (1985)

3. H. Botma, P.J.M. Peters, W.J. Witteman: Paper presented at Eighth International Symposium on Gas Flow and Chemical Lasers, Madrid, Spain, 10-14 September (1990) 
4. F.S. Collier, P. Labastie, M. Maillet, M. Michon: IEEE J. QE-19, 1129-1133 (1983)

5. J.E. Tucker, B.L. Wexler, B.J. Feldman, T. McClelland: IEEE Phot. Techn. Lett. 1, 193-195 (1989)

6. P.J.M. Peters, Qi-Chu Mei, W.J. Witteman: Appl. Phys. Lett. 54, 193-195 (1989)

7. E.L. Patterson, G.E. Samlin, P.J. Brannon: Results of Atomic Xe Laser Operation at High Energy Loadings, Sandia Report, Sand89-0716; UC 414 (1989)
8. S.A. Lawton, J.B. Richards, L.A. Newman, L. Specht, T.A. De Temple: J. Appl. Phys. 50, 3888-3898 (1979)

9. W.J. Alford, G.N. Hays. J. Apl. Phys. 65, 3760-3766 (1989)

10. C.L. Gordon III, B. Feldman, C.P. Christensen: Opt. Lett. 13, 114-116 (1988)

11. M. Ohwa, T.J. Moratz, M.J. Kushner: J. Appl. Phys. 66, 51315145 (1989)

12. P.J. Peters, Y.F. Lan, M. Ohwa, M.J. Kushner: IEEE J. QE-26, 1964-1970 (1990) 